\title{
Students' Reasons for Preferences of Contexts in Learning Mathematics
}

\author{
Mercy Kazima \\ Correspondence: Mercy Kazima, Department of Curriculum and Teaching Studies, University of Malawi, Malawi
}

Received: February 25, 2015 Accepted: March 19, 2015 Online Published: March 31, 2015

doi:10.11114/jets.v3i3.687

URL: http://dx.doi.org/10.11114/jets.v3i3.687

\begin{abstract}
This paper reports on findings from a study that investigated reasons Malawian students have for preferring particular contexts in mathematics. The study explored students' preferences of contexts using a survey questionnaire that contained 27 contexts and asked students to indicate their level of interest for each context on a 4-point scale and to write down reasons for their most preferred contexts. There were 393 students of 14-20 years old. Findings include that most preferred contexts were of future career prospects, modern technology, health and community issues. Students' reasons for these preferences were in four categories of career prospects, curiosity, community well-being and personal well-being. Furthermore, future career prospects was the most common reason for the preferred contexts.
\end{abstract}

Keywords: Malawi, contexts, interest, motivation, preferences, secondary school

\section{Introduction}

Many studies that have investigated use of contexts in mathematics teaching and learning, for example, Boaler (1993) and Nalube (2007), argue that use of learners' everyday contexts enhances their understanding and appreciation of mathematics. Furthermore many national curricula have relevance as one of their goals of education, for example Malawi's education goals have relevance as one of the four pillars (others are access, equity and quality) the nation aims to achieve through its education (Government of Malawi, 2008). Use of contexts derived from learners' real world is one way of achieving this relevance. Decisions about the kind of contexts to use are often made by developers of curriculum materials such as test developers, authors of textbooks and teachers. Very little is known about the contexts that learners would prefer to learn about in mathematics. This lack of literature on what students would find interesting as contexts in learning mathematics motivated a multinational study on relevance of school mathematics education (ROSME) project (Julie \& Holtman, 2008). The ROSME studies have provided information on what students in different parts of the world would prefer as contexts; for example in Swaziland (Ngcobo \& Julie, 2012), in Zimbabwe (Ndemo \& Mtetwa, 2010), in Albania (Kacerja, Julie \& Hadjerrouit, 2010; Kacerja, 2011), in South Africa (Julie \& Mbekwa, 2005; Julie, 2012) and in South Korea (Kim, 2012). For most of these studies, reasons for the preferences of students for particular contexts have been explained in terms of the contemporary issues prevailing in the students' society and through the authors' insights of the society. Ngcobo and Julie (2012) and Kacerja (2011) explored students' reasons for their preferences, and point to the limited research in this area. The study reported in this paper explored the reasons students in Malawi have for their most preferred school mathematics contexts, thus the study contributes to filling the gap of limited research in this field.

The study was a follow up on a study a year before that investigated students preferences using a survey questionnaire adapted from ROSME. I will refer to these as first study and second study. The first study used quantitative methods to determine students' preferences and suggested reasons for the preferences according to contemporary issues in Malawi (see Kazima, 2013). The second study repeated the same survey on a different cohort of students and further asked the students to give reasons for their most preferred contexts. The research question was (i) what would students prefer to learn as contexts in school mathematics and (ii) what reasons would students have for their preferences. Knowing students reasons for preferences is important and can greatly inform curriculum developers, textbook writers, developers of other teaching and learning materials, and teachers.

\section{Literature Review}

All the ROSME studies (Julie \& Holtman, 2008; Ndemo \& Mtetwa, 2010; Kacerja, Julie \& Hadjerrouit, 2010; Kacerja , 2011; Ngcobo \& Julie, 2012; Kim, 2012; Julie, 2012) and others, such as Kaiser-Messmer (1993) and Kazima (2013), confirm that secondary school students have preferences for contexts that can be used in teaching and learning mathematics and that these can be determined. The studies also reveal some similarities as well as differences between 
preferences of students from the various countries. For example, students from all the countries indicated preference for contexts that involved modern technology such as computer games, secret codes and electronic messaging. Some differences were noted between the countries in the North, Norway and South Korea, which are well developed and the countries in the South which are less developed. For example the African students rated contexts of high level professionals and profit making much higher than the students from Korea and Norway (Julie \& Holtman, 2008). Furthermore, there were other similarities in preferences by students from South Africa, Swaziland, Uganda and Zimbabwe, but not similar to those of Norway and Korea. This is not surprising because students from the African countries live in fairly similar societies and different from Norway and South Korea.

Ngcobo and Julie (2012) analysed the reasons that students in Swaziland, average age 14-16 years, gave for their most preferred contexts and suggested two categories of reasons and subcategories. The first category was that of future related reasons with four subcategories of (i) access to university, (ii) career prospects, (iii) financial power or gain and (iv) business prospects. The second was that of learning with two subcategories of (i) learning mathematics and (ii) learning generally. From their findings the most common reasons were the future related reasons, and within that category the most common subcategory was career prospects. Thus students' preferences for contexts were mostly influenced by their perceived career prospects. Kacerja et. al. (2010) found that among the top most preferred contexts by Albanian students were community issues, technology, planning a journey, and health issues. Kacerja et. al. (2010: 324) explained these preferences in terms of the issues affecting Albania at the time. For example, the highest preference for community issues, which was about "determining the level of development regarding employment, education and poverty of my community" indicated that the students were sensitive to the conditions in their communities where unemployment and poverty was common. The students seemed to see the need for such contexts which appeared to offer solutions for their situations.

In a later study, Kaceraj (2011) investigated reasons for Albanian students' preferences for contexts. This was done after offering a sample of secondary school students, in grades 8 and 9, some mathematics lessons using five specific contexts for the mathematics. The contexts, which were informed by the earlier study, were: development indexes, secret codes, sending SMSs, sport tournaments, and lotteries and gambling. Findings from this study included that students' reasons were motivated by new knowledge that they learnt in the lessons, perceived usefulness and relevance of the topic, community matters, and their own personal interest in the context, among other motives. He also found that the mathematics content itself and how difficult or easy it was for the students contributed to learners preferences. He therefore advises that learners preferences should be regarded with care. There is a difference between the Albania study and others such as Ngcobo and Julie (2012) in that the Albania study offered lessons which were of different mathematical content across the five contexts, as such the preferences were likely to also be influenced by the liking of specific kinds of mathematics, apart from the real life contexts and the level of difficulty of the topics.

In my first study (see Kazima (2013)), I adapted the ROSME questionnaire survey and used it to collect responses from 346 secondary students in Malawi most of whom were aged between 15 and 17 years. The modified questionnaire had 27 contexts which students were asked to rate on a four point scale from "not at all interested" to "very interested". Findings of this study included that students indicated high preferences for future prospects, modern technology, community issues, social issues and health issues. This was more or less similar to ROSME study findings in the African countries. Reasons for the preferences were explained from my knowledge and insights of Malawi issues and environment. For example, students' preference for contexts that offer future prospects indicated the students' desire for better lives in future because the students were mostly from rural areas where levels of poverty and unemployment are very high. The study however, did not solicit reasons from the students. This lack of students' reasons motivated the second study which sought to explore the students' reasons for their preferences of contexts to be used in mathematics.

\section{Conceptual Framework}

Conceptual framework that informed this study was adapted from Ngcobo and Julie (2012) who drew their framework from three types of constructs; generalized others, identity and environment. Referring to the work of Sfard and Prusak (2005) they describe social identity, instrumental identity and mathematical self identity as three forms of identity. They also refer to Alrø, Skovsmose and Valero (2009) and describe background and foregrounds as two constructs of people's environment which impact on the people's actions. From these Ngcobo and Julie (2012: 293) present what they call a "multifaceted framework". This framework suggests that the social environment influences the most preferred contexts and also influences each of the three forms of identities, and each of these influences the reasons for most preferred contexts. I have adapted this framework and have made one modification because I think that the most preferred contexts should not be shown to be directly influenced by the environment but rather should follow at the end of the line; from environment to identity to reasons to preferences for contexts (see figure 1). Thus in the modified framework, I agree with Ngcobo and Julie (2012) that the environment shapes formation of identity and that these identities influence the reasons for preferences. However, I further suggest that it is the reasons that determine the preferences and not that 
the environment directly influences the preferences, as Ngcobo and Julie (2012) suggest.

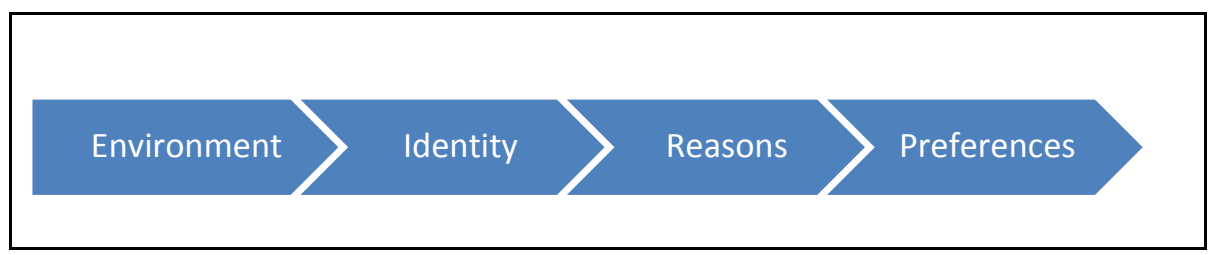

Figure 1. Conceptual framework modified from Ngcobo and Julie (2012)

\section{Methodology}

The first study administered a survey questionnaire which was modified from ROSME project and had a total of 27 contexts which students were asked to rate on a four point scale as (1) not at all interested or (2) a bit interested or (3) quiet interested or (4) very interested. The questionnaire was administered at the end of school year, at which time the students had three years of secondary school mathematics. The responses were analysed using frequency counts and students' preferences were ranked and classified into top 9, middle 9 and bottom 9 preferred contexts (see Kazima (2013) for details). The second study which is reported in this paper was a follow up of the first study. The questionnaire was revised to add one more item that asked students to give reasons for their five most preferred contexts. Thus the revised questionnaire had two parts; first part was exactly as before, it contained the same 27 contexts and asked students to indicate their level of interest on the same four point scale from (1) not at all interested to (4) very interested. The second part asked students to write down reasons for their five most preferred contexts out of the 27. The questionnaire was administered to a similar sample of students in the same schools a year later. There were a total of 393 students; 154 female and 239 male. Their ages ranged from 14 to 20 years with most being 15-18 years old. The same quantitative analysis of frequency counts was done to rank the 27 contexts in descending order from most preferred to least preferred. Furthermore, the top ten most preferred contexts were classified into categories which were informed by earlier studies. For the second part of questionnaire, qualitative methods were employed to analyse the reasons students gave for their most preferred contexts. The first stage of the qualitative analysis was reading and recording all the reasons given by the students for each of the contexts that were mentioned as one of their most preferred. The second stage was finding patterns and themes of the reasons within each context, and the third stage was comparing the themes and patterns across the contexts. Final stage was consolidating these into one list of categories and using frequencies to rank these from most to least mentioned reasons. For this paper I will focus only on the reasons given for the overall top ten most preferred contexts. The 27 contexts were coded as MC1, MC2, ..., MC27. MC for Mathematics Context.

\section{Findings and Discussion}

\subsection{Top Ten Most Preferred Contexts}

Table 1. Students' top ten preferences of contexts from most to least preferred

\begin{tabular}{|c|c|}
\hline Rank & Description \\
\hline 1 & Mathematics that will help me to do mathematics at universities or other colleges (MC19) \\
\hline 2 & Mathematics that is relevant to professionals such as engineers, lawyers and accountants (MC12) \\
\hline 3 & Mathematics involved in secret codes such as pin numbers used for withdrawing money from ATM (MC18) \\
\hline 4 & Mathematics involved in working out financial plans for profit-making (MC23) \\
\hline 5 & Mathematics to prescribe the amount of medicine a sick person must take (MC7) \\
\hline 6 & Mathematics involved in making computer games, cell phone games and TV games (MC1) \\
\hline 7 & Mathematics involved in sending and receiving of electronic messages such as SMS and e-mail (MC3) \\
\hline 8 & Mathematics linked to the spread and decline of epidemics such as AIDS, TB and cholera (M25) \\
\hline 9 & Mathematics involved in issues of population growth and the impact on communities (MC13) \\
\hline 10 & $\begin{array}{l}\text { Mathematics involved in determining the level of development regarding employment, education and } \\
\text { poverty of my community (MC27) }\end{array}$ \\
\hline
\end{tabular}

Table 1 shows the top ten contexts in descending order of students' preferences

The top ten most preferred contexts can be categorized into four; (i) those that have to do with future prospects (MC19, MC12 and MC23), (ii) those to do with modern technology (MC18, MC1 and MC3), (iii) those to do with health (MC7 and MC25) and (iv) those to do with community (MC13 and MC27). This is similar to the findings of the first study, where the students also preferred these contexts most although in a slightly different order. Furthermore the top two most preferred were exactly the same; MC19 followed by MC12. This shows consistency in the students' preferences across cohorts.

\subsection{Reasons for Top Ten Most Preferred Contexts}

From my insight and knowledge of community environments in Malawi, most of the reasons students gave were as 
expected. Specifically for future prospects it was expected that students would have reasons of desire for further education and to become lawyers, engineers, successful businessmen or other high level professionals. Reason expected for preferring technology contexts was that of curiosity. For health issues I expected personal well-being and community well-being to be the reasons while for community issues I expected community well-being. Analysis of the actual reasons given by all the students for the various categories classified them into four themes; (i) career prospects, (ii) curiosity, (iii) community well-being and (iv) personal well-being. Table 2 shows how these were spread across the four categories of contexts; future prospects; modern technology; health and community. The last column gives examples of the responses by students which were classified under each of the themes.

Table 2. Students' reasons for preferences by category and theme

\begin{tabular}{|c|c|c|}
\hline $\begin{array}{l}\text { Category of } \\
\text { context }\end{array}$ & $\begin{array}{l}\text { Theme of reasons } \\
\text { by students }\end{array}$ & Examples \\
\hline $\begin{array}{l}\text { Future } \\
\text { prospects }\end{array}$ & career prospects & $\begin{array}{l}\text { "because I want to be a good engineer" } \\
\text { "my ambition is to become a profitable businessman" } \\
\text { "I want to go to university" } \\
\text { "to become a lawyer" } \\
\text { "so that I will be an accountant" } \\
\text { "will help me succeed in business" }\end{array}$ \\
\hline \multirow[b]{2}{*}{ Technology } & career prospects & $\begin{array}{l}\text { "I want to be computers engineer" } \\
\text { "I shall not have problems in finding a job" } \\
\text { "I am interested in technology ... I want to be technician" }\end{array}$ \\
\hline & curiosity & $\begin{array}{l}\text { I am very interested in this because I want to know how ATM works" } \\
\text { "I want to know how secret codes and pin codes work" } \\
\text { "Because when I see games on computer etc. I get confused to how they made } \\
\text { them so is my wish to know how the games are performed } \\
\text { "to become a doctor and help people" }\end{array}$ \\
\hline \multirow{5}{*}{ Health } & \multirow{4}{*}{$\begin{array}{l}\text { community well } \\
\text { being }\end{array}$} & $\begin{array}{l}\text { "This may help us to be aware of what is causing many people to be affected by } \\
\text { diseases and students like me who want to become doctors would be very } \\
\text { interested in knowing more }\end{array}$ \\
\hline & & "to help people be healthy" \\
\hline & & "reduce the diseases among people" \\
\hline & & $\begin{array}{l}\text { "health matters because people can be able to do anything to improve their way of } \\
\text { living" }\end{array}$ \\
\hline & $\begin{array}{l}\text { personal well } \\
\text { being }\end{array}$ & $\begin{array}{l}\text { "I want to be healthy" } \\
\text { "to know how I can prevent such diseases" } \\
\text { "this will help me overcome the problem of diseases" }\end{array}$ \\
\hline Community & $\begin{array}{l}\text { community well } \\
\text { being }\end{array}$ & "I want to help people in my community in future" \\
\hline
\end{tabular}

Looking at the reasons given by the students, it is interesting to note that the desire for future career prospects was also one of the reasons for preferring technology and health issues. For example, responses like "I want to be a doctor", "I want to be a technician" and "I shall not have problems finding a job (if I know about technology)" were common. Some students had more than one reason in their responses, for example "I want to work in a bank and want to know how ATM works", "to be a doctor and help people in my community", and "to be aware of what is causing many people to be affected by diseases and students like me who want to become doctors want to know more". The first response shows curiosity in wanting to know how ATM works and also the desire for future job with a bank. The other two about health issues show ambition to become doctors as well as concern for the well-being of their communities and people in Malawi. This reason of career prospects for preferring health and technology contexts was something that I did not expect or envision. It was therefore intriguing to note that it was a common reason among the students. This might also explain the students' lack of interest in contexts related to agriculture and ethnomathematics; that students are not interested in having careers in these areas. Ranking of all the 27 contexts revealed that agriculture and ethnomathematics were among the least preferred contexts. It should be noted that the agriculture that the Malawi students are exposed to is small scale farming that most of their families and communities do for their food and livelihood, and therefore not appealing to them as careers. Similarly, the ethnomathematics of basket or mat weaving context is not appealing as a career prospect for the students, probably because in Malawi these are often done by people with little or no education.

Further analysis of the four themes used frequencies to indicate most common reasons for the students preferences. 


\subsection{Most Common Reasons in Terms of Theme}

Table 3. Students' most common reasons in terms of theme

\begin{tabular}{llc}
\hline & Theme & Frequency \\
\hline 1 & career prospects & 258 \\
2 & curiosity & 102 \\
3 & community well-being & 51 \\
4 & personal well-being & 28 \\
\hline
\end{tabular}

As can be seen from table 3, the most common reasons by theme and in descending order of frequencies were: career prospects, curiosity, community well-being, and personal well-being. The frequencies indicate the number of students that gave the particular theme of reason. As mentioned earlier, many of the students gave more than one kind of reason and hence the total is more than the number of students. Looking at these frequencies we note that career prospects was by far the most common reason indicating that most of the students aspire for successful careers that offer a better life. Ngcobo and Julie (2012) also found that future related reasons were the most common among Swaziland students. Curiosity was also a common reason especially where modern technology was concerned. It should be noted that in Malawi most of the modern technologies are fairly recent and many people are curious about how they work. Community well-being was third most common reason which shows that many of the students are sensitive to their situations and have desire to improve their situations. This is similar to the findings of Kacerja (2011) where students demonstrated concerns for their communities in their preferences for contexts to be used in mathematics. Personal well-being was also a reason for preferring certain contexts, especially health issues, although not very common compared to the others. Still it is interesting that learners are aware of the need for their health to be in good condition for them to become useful members of their communities.

The frequencies for the various themes of reasons reveal that the most important thing for the students is to get an education that will enable them to have god jobs in future and be able to lead productive lives. This might seem obvious to many but it is important to acknowledge these ambitions and interests that students have and use them to inform our teaching of mathematics through development of curriculum materials, teaching resources and actual classroom teaching.

Relating the findings to the conceptual framework, we note that the students' reasons are influenced by their identities which in turn are influenced by their environment; the students' environment shapes their identities which further shape their reasons for their preferences. The finding that most of the reasons are about future career prospects, can be explained that the students environment; their backgrounds (which include poverty and unemployment) and foregrounds (which is about ambitions of better life) shape their identities (social, instrumental and self mathematical) and influence their reasons for preferences (mathematics that offer opportunities for development of their future aspirations). The other reasons can also be explained in a similar way, for example the reason of 'community well-being' originates from the students' environment especially their backgrounds which influence their identities and further influences their reasons and preferences of issues that offer opportunities to improve the well-being of their communities.

I argued earlier that knowing students' preferences would inform developers of curriculum materials and teachers. Having known the contexts preferred by the students in this study, their teachers could incorporate these in their selection of contexts for teaching mathematics. For example, the teachers could avoid contexts of farming, fishing or weaving and opt for contexts of technology and future prospects. However, this might not be as easy as it sounds and might take much more time than teachers have.

Curriculum materials developers might have the time and resources to include the students' preferred contexts, but there are other complexities that might arise. These include; catering for different communities of students that might have different interests, and the time frame within which they can expect the interests to be similar across cohorts of students.

\section{Conclusion}

In this paper I have discussed findings of a study that sought reasons for students' preferences for contexts in learning mathematics. The study's findings show that the most preferred contexts were similar to those by students in the first study, and also similar to findings from other studies, especially in Africa. The reasons students gave for their preferences were mostly about career prospects in their future. Other reasons were curiosity, community and personal well-being. Students' interest in their future career prospects, was also observed by Ngcobo and Julie (2012) and students' concern for their communities was also observed by Karceja (2011), thus confirming findings of earlier studies. However, the finding that students preferences for technology and health issues are also influenced by their desire for future careers in these areas is new and hence the contribution of this study. Finally, I have discussed that while the findings are useful and could inform mathematics teachers and developers of curriculum materials, there are some 
complexities that might arise during implementation.

\section{References}

Alrø, H., Skovsmose, O., \& Valero, P. (2009). Inter-viewing foregrounds: students motives for learning in a multicultural settings. In M. Ceasar \& K.Kumpulainen (Eds.), Social interactions in multicultural settings (pp. 13-37). Rotterdam: Sense Publishers.

Boaler, J. (1993). The role of contexts in the mathematics classroom: Do they make mathematics more real? For the learning of mathematics, 13(2), 12-17.

Government of Malawi (2008). National Education Sector Policy and Plan (NESP). Lilongwe: Ministry of Education.

Julie, C. (2012). The stability of learners' choices for real-life situations to be used in mathematics. International Journal of Mathematical Education in Science and Technology, 44(20), 196-203.

Julie, C., \& Mbekwa, M. (2005). What would Grade 8 to 10 learners prefer as context for mathematical literacy? The case of Masilakele Secondary School. Perspectives in Education, 23(3), 31-43.

Julie, C., \& Holtman, L. (2008). The relevance of school mathematics education (ROSME). In L. Holtman, C. Julie, Ø. Mikalsen, D. Mtetwa, \& M. Ogunniyi (Eds.), Some developments in research in science and mathematics in Sub-Saharan Africa: Access, relevance, learning, curriculum research (pp. 379-405). Somerset West, South Africa: African Minds.

Kacerja, S. (2011). Albanian students' motives for preferring certain real-life situations for learning mathematics. Pythagoras, 32(2), Art. \#50, 9 pages. http://dx.doi.org/10.4102/ pythagoras.v32i2.50

Kacerja, S., Julie, C., \& Hadjerrouit, S. (2010). The contexts Albanian students prefer to use in Mathematics and relationship to contemporary matters in Albania. In V. Mudal, Research in Mathematics, Science and Technology Education, , 1, 319-328. Durban: SAARMSTE.

Kaiser-Messmer, G. (1993). Results of an empirical study into gender differences in attitudes towards mathematics. Educational Studies in Mathematics, 25, 209-233. http://dx.doi.org/10.1007/BF01273862

Kazima, M. (2013) Students' Preferences for Contexts and their Relevance to School Mathematics in Malawi, African Journal of Research in Mathematics, Science and Technology Education, 17(3), 244-254

Kim, S. (2012) Preferred contexts of Korean youth for the lerning of school mathematics. Unpublished doctoral theses. Bellville: University of the Western Cape.

Nalube, P. (2007). Establishing links between classroom mathematics and everyday life of learners. Proceedings of workshop on Modeling in Mathematics Learning, Makerere University, Uganda, 46-52.

Ndemo, Z., \& Mtetwa, D. (2010). Preferences of contexts for learning mathematics expressed by students in rural secondary school environments of Zimbabwe. Zimbabwe Journal of Educational Research, 22(1), 1-15.

Ngcobo, M., \& Julie, C. (2012). Contexts preferred for use in mathematics by Swaziland high performing public schools' junior secondary learners. African Journal of Research in Mathematics, Science and Technology Education, 16(3), 289-301.

Sfard, A., \& Prusak, A. (2005). Telling identities: in search of an anlystic tool for investigating learning as a culturally shaped activity. Educational Researcher, 34(4), 14-22. http://dx.doi.org/10.3102/0013189X034004014

This work is licensed under a Creative Commons Attribution 3.0 License. 